\title{
In Vitro Lead Tolerance Testing in White Poplar Genotypes on Acidic Medium
}

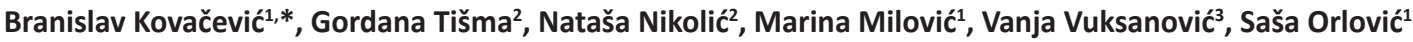

(1) University of Novi Sad, Institute of Lowland Forestry and Environment, Antona Čehova 13, RS-21000 Novi Sad, Serbia; (2) University of Novi Sad, Faculty of Sciences, Trg Dositeja Obradovića 3, RS-21001 Novi Sad, Serbia; (3) University of Novi Sad, Faculty of Agriculture, Trg Dositeja Obradovića 8, RS-21002 Novi Sad, Serbia

* Correspondence: e-mail: branek@uns.ac.rs
Citation: Kovačević $B$, Tišma G, Nikolić N, Milović M, Vuksanović V, Orlović S, 2020. In Vitro Lead Tolerance in White Poplar Genotypes on Acidic Medium. Southeast Eur for 11(2): 153-160. https://doi. org/10.15177/seefor.20-18.

Received: 20 Oct 2020; Revised: 19 Nov 2020; Accepted: 20 Nov 2020; Published online: 14 Dec 2020

\begin{abstract}
This study evaluates in vitro tolerance of white poplar genotypes to the presence of lead in an acidic rooting medium. Lead was supplemented in form of $\mathrm{Pb}\left(\mathrm{NO}_{3}\right)_{2}$, in the following concentrations: $0 \mathrm{M}$ (Control), $10^{-6} \mathrm{M}, 10^{-5} \mathrm{M}, 10^{-4} \mathrm{M}$ and $10^{-3}$ M. After four weeks of cultivation, the following characters were measured: number of roots, the length of the longest root, the shoot height, dry root mass and dry shoot mass, and parameters related to photosynthetic pigments: content of chlorophyll $a, b, a+b$, and of carotenoids in fresh mass, as well as chlorophyll $a / b$ ratio. For further statistical analysis, tolerance indices by Turner and Marshal (TI) were calculated for each measured character. The strongest inhibitory effect was achieved on the medium with $10^{-4} \mathrm{M} \mathrm{Pb}\left(\mathrm{NO}_{3}\right)_{2}$, but the best differentiation between genotypes was achieved on the medium with $10^{-5} \mathrm{M} \mathrm{Pb}\left(\mathrm{NO}_{3}\right)_{2}$. The highest tolerance indices for the length of the longest root and shoot height had genotypes L-12 and LBM, and for root and shoot dry mass genotypes LCM and L-12. There were no significant differences between genotypes in tolerance indices by any of the examined photosynthetic parameters. The obtained results suggest that both low $\mathrm{pH}$ and the presence of citric acid as chelating agent improved evaluation of lead tolerance in comparison with the results obtained on media with standard $\mathrm{pH}$ and without citric acid in similar studies. In vitro tests on acidic medium with citric acid can efficiently differentiate examined genotypes for lead tolerance, which could be important for their use in phytoextraction projects, especially on acidic soils.
\end{abstract}

Keywords: Populus alba; heavy metals; low pH; microwave sterilization

\section{INTRODUCTION}

With the start of the rapid development of mining and industrialization at the end of the $19^{\text {th }}$ century, the ecosystems have been constantly polluted by a wide variety of heavy metals (Benavides et al. 2005). Accumulated in sufficient quantities, heavy metals not only pose serious problems to plant growth and development, but to human health as well (Arora et al. 2008).

Lead is a heavy metal that is considered one of the most toxic metals (Zhang 2003), and the major pollutant in both terrestrial and aquatic ecosystems (Sharma and Dubey 2005). Lead naturally occurs in the soil, but its content can be greatly increased by human activities (Seregin and Ivanov 2001). River sediments also receive significant anthropogenic loads of metals from both point and nonpoint sources (Sakan et al. 2009).

Apart from negative effects on membrane structure, water potential, and hormonal status, its toxicity is mostly related to oxidative stress by increased accumulation of free radicals and reactive oxygen species. Lead stimulates this process by affecting enzyme activity and inhibition of electron transport during oxidative phosphorylation (Seregin and Ivanov 2001, Sharma and Dubey 2005, Zengin and Munzuroglu 2005).

Phytoextraction is an environmentally friendly in situ technique for cleaning up metal from contaminated land. By phytoextraction toxic metals are taken out from contaminated soil and accumulated in the above-ground tissues of higher plants, which is sometimes assisted with 
different chelating agents in order to increase the efficiency (Pulford and Watson 2003, Sinhal et al. 2010).

Poplars are often used in phytoremediation. Their main advantages are fast growth, adaptability, well-developed root system that reaches underground waters, the ability to transpire considerable amounts of water (Aitchison et al. 2000), and the possibility of the establishment of short coppice culture (Rockwood et al. 2000). Poplars could be compared to the hyperaccumulators in the heavy metal accumulation by large biomass production (Pulford and Watson 2003) and relatively high quantity of extracted metal per plant (di Lonardo et al. 2011). White poplars (Populus section Populus) are interesting for their higher tolerance to drought and salinity compared to black poplars ( $P$. section Aigeiros Duby).

Considering limitations of field studies on large longlived organisms, the use of in vitro culture of tree species remains an interesting technique for studying the effects of elevated levels of heavy metals and the selection of heavy metal-tolerant genotypes. Developmental and molecular data obtained by Castiglione et al. (2007) in white poplar support the use of in vitro techniques in the study of heavy metal stress responses. Tolerance of white poplars to heavy metals, including lead, has been tested in controlled conditions, and differences among genotypes were found (Kališova-Špirochova et al. 2003, Bojarczuk 2004, Bittsanszky et al. 2005, Katanic et al. 2007, 2008, di Lonardo et al. 2011). Nowadays, these tests include the use of media that increase bioavailability and mobility of heavy metals by lowering $\mathrm{pH}$ and the use of chelators (Vuksanović et al. 2017a).

In this research, the effect of lead on morphometric parameters, biomass accumulation, and content of photosynthetic pigments in five white poplar (Populus alba L.) genotypes in vitro was studied. The aim was to evaluate and select lead-tolerant white poplar genotypes cultured in vitro on acidic medium in the presence of citric acid, regarding the possible use of these genotypes in phytoremediation projects on acidic and lead-contaminated soils.

\section{MATERIALS AND METHODS}

\section{Plant Material and Shoot Multiplication}

Five white poplar genotypes were examined: Villafranca (Italy), L-12 (Serbia), L-80 (Serbia), LBM (Serbia), and LCM (Serbia). These genotypes have been proved suitable for biomass production, landscaping, and horticulture and suitable for in vitro testing to abiotic stresses (Kovačević et al. 2013a, Vuksanović et al. 2016, 2019a). According to Kovačević and Igić (2018) and Kovačević et al. (2020), Villafranca, L-12 and L-80 genotypes are characterized by relatively good rooting of hardwood cuttings. Also, special attention is paid to L-12 genotype due to its high biomass production and wood characteristics (Ištok et al. 2019, Sedlar et al. 2019).

Micropropagation of five tested genotypes was performed by shoot tips and axillary buds to preserve clonal fidelity (Rani and Raina 2000, Confalonieri et al. 2003). The medium used in shoot multiplication has been described by Kovačević et al. (2013a).
The cultures were kept at $26 \pm 2^{\circ} \mathrm{C}$ in the white fluorescent light ( $3500 \mathrm{lux} \cdot \mathrm{m}^{-2}$ ) with a 16 -hour photoperiod and subcultured at 4-week intervals.

\section{Lead Treatments}

For the experiment, $2.0 \mathrm{~cm}$ long shoot tips from micro shoots gained from the multiplication phase were placed on rooting ACM medium containing no hormones, adjusted to $\mathrm{pH} 3$ before sterilization. Citric acid was added to provide pH stability (Skirvin et al. 1986). By lowering the medium $\mathrm{pH}$ and by acting as a chelating agent, citric acid was expected to improve lead uptake by plants and to achieve more critical tests for lead tolerance.

The following concentrations of lead in form of $\mathrm{Pb}\left(\mathrm{NO}_{3}\right)_{2}$ were examined: $0 \mathrm{M}$ (as a Control), $10^{-6} \mathrm{M}, 10^{-5} \mathrm{M}, 10^{-4} \mathrm{M}$, and $10^{-3} \mathrm{M}$, labeled L0, L1, L2, L3, and L4, respectively.

The sterilization of media was performed by the microwave oven. The media were heated until they started to boil and then poured into sterilized jars in the laminar chamber, in order to preserve the jellification potential of agar that could be compromised by low medium $\mathrm{pH}$ (Kovačević et al. 2013b, Vuksanović et al. 2016, 2017a).

The cultures were kept for 4 weeks, at the same conditions as cultures for shoot multiplication. Three jars with five plants per jar were set per each Genotype $\times$ Medium combination. For pigment content determination, additional three jars with five shoots per jar were established per each Genotype $\times$ Medium treatment.

\section{Lead Tolerance Assessment}

After four weeks of cultivation, the following morphometric characters were determined: the number of roots per plant, the length of the longest root per plant, and the height of the shoot.

The following characters describing biomass were determined: dry root mass per plant and dry shoot biomass accumulation per plant. For dry shoot biomass accumulation, fifteen rootless shoot tips were dried at $70^{\circ} \mathrm{C}$ for 72 hours and then weighted. The dry shoot biomass accumulation was calculated as a difference between dry shoot biomass at the beginning and at the end of the experiment. The dry mass root/shoot ratio was calculated, as well as the ratio between dry root and dry shoot biomass accumulation.

Content of photosynthetic pigments in fresh shoot mass for chlorophyll a ( $\mathrm{Chl}$ a), chlorophyll b (Chl b) and total carotenoids was determined spectrophotometrically (Wettstein 1957). The chlorophyll $a+b$ and chlorophyll $a / b$ ratio were then calculated.

The toxicity of the applied lead concentration and differences in lead tolerance among the examined genotypes were evaluated by tolerance indices. The tolerance index (TI) was calculated according to Turner and Marshal (1972), as a ratio between the value of a parameter on the medium with a particular lead concentration $\left(\mathrm{X}_{\mathrm{c}(\mathrm{Pb})}\right)$ and the value obtained on the control $\left(X_{\text {control }}\right)$ (Equation 1$)$ :

$$
T I=\frac{X_{C(P b)}}{X_{\text {Control }}}
$$




\section{Statistical Analysis}

The whole experiment was designed as completely randomized. The obtained data were analyzed by twoway factorial analysis of variance, as well as Fisher's Least significant difference test (LSD test) with STATISTICA 13 statistical program (TIBCO Software Inc. 2017).

\section{RESULTS}

\section{Morphometric Characters}

No obvious signs of toxicity, like chlorosis, necrosis, or decay of shoot tissue, were observed, and the rooting of shoots was nearly $100 \%$ on all examined media (Figure 1). Only on $\mathrm{L} 4$ medium (with $10^{-3} \mathrm{M} \mathrm{Pb}\left(\mathrm{NO}_{3}\right)_{2}$ ) the partial darkening of roots was noticed. The results for the measured characters are given in Supplementary File.

Factor Genotype had significant effect on the tolerance indices of measured morphometric characters, except for the length of the longest root. The effect of lead concentration was significant for the length of the longest root and shoot height, while interaction Genotype $\times$ Medium had no significant influence on any of the examined morphometric characters (Table 1). Since there was no significant effect of factor Medium, as well as of interaction Genotype $x$ Medium on tolerance index based on the number of roots, data from further statistical analysis for this parameter are not presented.

According to the LSD test for tolerance, indices for the length of the longest root on L3 and L4 were significantly lower than on L1 and L2 media. In total, the highest tolerance index for the length of the longest root had genotype L-12, and the lowest genotype L-80. The best differentiation of genotypes by this tolerance index was found on $L 2$ medium. On this medium tolerance index for the length of the longest root for genotype L-80 was lower than for other examined genotypes (Table 2).

In total, the reaction of most of the examined poplar genotypes to lead treatments by shoot height appeared to be similar as by the length of the longest root, except for genotype L-80 which achieved significantly slower growth than others. Except significantly smaller tolerance index for

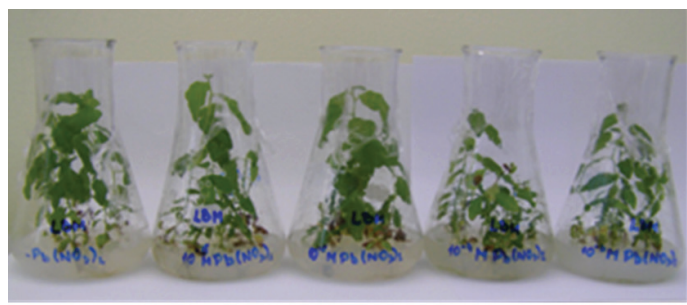

(a)

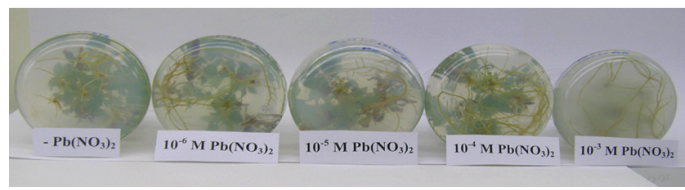

(b)

Figure 1. Rooted microshoots of genotype LBM after four weeks of in vitro cultivation on examined concentrations of $\mathrm{Pb}\left(\mathrm{NO}_{3}\right)_{2}$ : (a) Shoots; (b) Root system.

Table 1. Results of F-test for tolerance indices based on the examined characters.

1) Labels for F-test: ${ }^{*}$ - significant at the level $\alpha=0.05 ;{ }^{* *}$ - significant at the level $\alpha=0.01$

\begin{tabular}{|c|c|c|c|}
\hline \multirow{2}{*}{ Character } & \multicolumn{3}{|c|}{ Source of variation } \\
\hline & Genotype (A) & Medium (B) & Interaction $\mathrm{A} \times \mathrm{B}$ \\
\hline \multicolumn{4}{|c|}{ Morphometric characters } \\
\hline Number of roots & $13.48^{* * 11}$ & 2.15 & 0.75 \\
\hline The length of the longest root & 2.54 & $6.13^{* *}$ & 1.65 \\
\hline Shoot height & $5.58^{* *}$ & $7.38^{* *}$ & 0.94 \\
\hline \multicolumn{4}{|c|}{ Biomass characters } \\
\hline Dry root mass & $6.98^{* *}$ & $3.78^{*}$ & 1.62 \\
\hline Dry shoot mass & $7.71^{* *}$ & $3.12^{*}$ & $2.54^{*}$ \\
\hline Dry mass root/shoot ratio & $5.87^{* *}$ & 1.77 & 1.06 \\
\hline \multicolumn{4}{|c|}{ Content of photosynthetic pigments } \\
\hline Chlorophyll a content & 1.10 & $4.36^{*}$ & 1.53 \\
\hline Chlorophyll b content & 2.13 & $3.36^{*}$ & 1.5 \\
\hline Chlorophyll $\mathrm{a}+\mathrm{b}$ content & 1.45 & $4.22^{*}$ & 1.57 \\
\hline Carotenoids content & 0.59 & $3.97^{*}$ & 1.10 \\
\hline Chlorophyll a/b ratio & 1.90 & 1.11 & 0.82 \\
\hline
\end{tabular}


Table 2. Tolerance index for the length of the longest root and shoot height of the examined white poplar genotypes cultured on media with different lead concentrations (Fisher's LSD test).

$\left.{ }^{*}\right)$ The differences between values marked with the same letter are not significant at the level $\alpha=0.05$

\begin{tabular}{|c|c|c|c|c|c|c|c|c|c|c|c|}
\hline $\begin{array}{c}\mathrm{c}\left(\mathrm{Pb}\left(\mathrm{NO}_{3}\right)_{2}\right) \\
(\mathrm{M})\end{array}$ & \multicolumn{2}{|c|}{ Villafranca } & \multicolumn{2}{|l|}{ L-12 } & \multicolumn{2}{|c|}{ L-80 } & \multicolumn{2}{|c|}{ LBM } & \multicolumn{2}{|c|}{ LCM } & Total (Medium) \\
\hline \multicolumn{12}{|c|}{ Tolerance index for the length of the longest root } \\
\hline $10^{-6}$ & 1.03 abc & $\left.\operatorname{cdef}^{*}\right)$ & 1.57 a & & 1.39 & abc & 1.45 & a & 1.26 & abcd & 1.36 a \\
\hline $10^{-5}$ & 1.25 abc & & 1.49 a & & 0.55 & ef & 1.37 & a & 1.24 & abcd & $1.21 \mathrm{a}$ \\
\hline $10^{-4}$ & 0.72 def & & $1.13 \mathrm{abcc}$ & & 0.78 & bcdef & 1.10 & abcde & 0.75 & cdef & $0.93^{\mathrm{b}}$ \\
\hline $10^{-3}$ & 1.41 ab & & $0.94 \mathrm{abcc}$ & & 0.39 e & ef & 0.60 & f & 0.80 & bcdef & $0.85^{\mathrm{b}}$ \\
\hline Total (Genotype) & $1.10^{a b}$ & & 1.28 a & & 0.83 & b & 1.16 & a & 1.01 & ab & \\
\hline \multicolumn{12}{|c|}{ Tolerance index for shoot height } \\
\hline $10^{-6}$ & 1.07 & abcdeff $\left.{ }^{*}\right)$ & 1.34 & a & 0.94 & cdefghi & 1.24 & $a b c$ & 1.15 & abcde & 1.16 a \\
\hline $10^{-5}$ & 1.14 & abcdef & 1.29 & $a b$ & 0.81 & efghi & 1.15 & abcd & 0.99 & bcdefgh & 1.09 a \\
\hline $10^{-4}$ & 0.80 & fghi & 1.07 & abcdefg & 0.61 & $i$ & 1.02 & bcdefgh & 0.83 & efghi & 0.89 b \\
\hline $10^{-3}$ & 1.09 & abcdefg & 0.76 & ghi & 0.64 & hi & 0.96 & defgh & 0.97 & bcdefgh & $0.91 \quad b$ \\
\hline Total (Genotype) & 1.02 & a & 1.12 & a & 0.77 & $7 \mathrm{~b}$ & 1.10 & a & 0.98 & a & \\
\hline
\end{tabular}

shoot height of L-12 on medium L4 than on L1 and L2, there were no significant differences in the reaction of genotypes by morphometric characters on the examined media (Table 2).

\section{Biomass Characters}

All tolerance indices for biomass characters were significantly affected by both Genotype and Medium factors, except for the main effect of Medium on tolerance index for dry mass root/shoot ratio. The effect of interaction Genotype $\times$ Medium was significant only for dry shoot mass accumulation (Table 1). Since factor Medium and interaction Genotype $\times$ Medium did not achieve significant effect on tolerance index based on the number of roots, for this parameter data from further statistical analysis are not presented.

There was a significantly lower tolerance index for dry root mass accumulation on medium $\mathrm{L} 3\left(10^{-4} \mathrm{M} \mathrm{Pb}\left(\mathrm{NO}_{3}\right)_{2}\right)$, compared to other examined lead concentrations. In total, the highest tolerance indices for dry root mass accumulation achieved L-12 and LCM, and the lowest L-80. The best differentiation between genotypes was achieved on medium $\mathrm{L} 2\left(10^{-5} \mathrm{M} \mathrm{Pb}\left(\mathrm{NO}_{3}\right)_{2}\right)$, where L-12 and LCM had lower tolerance indices for dry root mass accumulation than L-80 and Villafranca (Table 3).

Table 3. Tolerance index for dry root and shoot mass of the examined white poplar genotypes on media with different lead concentrations (Fisher's LSD - test).

$\left.{ }^{*}\right)$ The differences between values marked with the same letter are not significant at the level $\alpha=0.05$

\begin{tabular}{|c|c|c|c|c|c|c|c|c|c|c|c|c|}
\hline $\begin{array}{c}\mathrm{c}\left(\mathrm{Pb}\left(\mathrm{NO}_{3}\right)_{2}\right) \\
(\mathrm{M})\end{array}$ & \multicolumn{2}{|c|}{ Villafranca } & \multicolumn{2}{|c|}{$\mathrm{L}-12$} & \multicolumn{2}{|c|}{$\mathrm{L}-80$} & \multicolumn{2}{|c|}{ LBM } & \multicolumn{2}{|c|}{ LCM } & \multicolumn{2}{|l|}{ Total (Medium) } \\
\hline \multicolumn{13}{|c|}{ Tolerance index for dry root mass } \\
\hline $10^{-6}$ & 1.00 & $\operatorname{cdefgh} *)$ & 2.06 & ab & 1.21 & bcdefgh & 1.75 & abcd & 1.58 & abcde & 1.56 & a \\
\hline $10^{-5}$ & 0.78 & efgh & 2.07 & $a b$ & 0.29 & h & 1.39 & bcdeg & 1.95 & $a b c$ & 1.31 & a \\
\hline $10^{-4}$ & 0.50 & $\mathrm{fgh}$ & 1.40 & bcdefg & 0.45 & fh & 0.52 & fh & 1.19 & bcdefgh & 0.77 & b \\
\hline $10^{-3}$ & 1.61 & abcde & 1.23 & bcdefgh & 0.61 & defgh & 0.71 & efgh & 2.50 & a & 1.34 & a \\
\hline Total (Genotype) & 0.97 & $\mathrm{~b}$ & 1.69 & a & 0.65 & b & 1.12 & b & 1.81 & a & & \\
\hline \multicolumn{13}{|c|}{ Tolerance index for dry shoot mass } \\
\hline $10^{-6}$ & 0.76 & $\left.f^{*}\right)$ & 1.74 & $a b c$ & 1.42 & cdef & 1.34 & cdef & $1.78 \mathrm{abc}$ & & 1.40 & a \\
\hline $10^{-5}$ & 0.82 & ef & 1.65 & bcd & 0.75 & $f$ & 1.46 & cde & $1.69 a b c$ & & 1.31 & $a b$ \\
\hline $10^{-4}$ & 0.80 & ef & 1.16 & cdef & 0.70 & $f$ & 0.80 & $f$ & $1.73 \mathrm{abc}$ & & 1.00 & b \\
\hline $10^{-3}$ & 1.03 & cdef & 0.87 & def & 2.64 & a & 0.92 & ef & 2.27 & & 1.37 & a \\
\hline Total (Genotype) & 0.85 & c & 1.36 & b & 1.20 & bc & 1.14 & $\mathrm{bc}$ & $1.87 \mathrm{a}$ & & & \\
\hline
\end{tabular}


In total, the lowest tolerance index for dry shoot mass accumulation was achieved on medium L3. The highest tolerance index in total for genotypes was achieved by LCM, and the lowest by genotype L-80. The best differentiation between genotypes was achieved on medium L2, where L-12 and LCM had significantly higher tolerance indices than genotypes L-80 and Villafranca (Table 3).

\section{Content of Photosynthetic Pigments}

Factor Medium had a significant effect on the variation of tolerance indices for all examined photosynthetic characters, except for chlorophyll a/b ratio (Table 1 ). Because there was no significant effect of any of the controlled sources of variation on tolerance index based on chlorophyll a/b ratio, data from further statistical analysis for this parameter are not presented. Also, results of LSD test for treatments of factor Genotype and interaction Genotype $\times$ Medium are not presented, because their effects were not significant for tolerance indices for any of examined photosynthetic pigments' traits.

The highest values of tolerance indices for the examined photosynthetic characters were gained on L4 medium (10$\left.{ }^{3} \mathrm{M} \mathrm{Pb}\left(\mathrm{NO}_{3}\right)_{2}\right)$ (Table 4). However, neither of the examined media was found to be useful in the differentiation of genotypes by tolerance indices for any of the examined photosynthetic traits.

\section{DISCUSSION}

The success of phytoremediation is considerably related to the ability of a plant to survive and grow in the presence of a pollutant in the growing substrate. This is particularly important for poplars, which have been well-recognized as species that play an important role in the phytoremediation of polluted sites. Some studies indicate that there is a small probability that the poplar plant would face lethal lead concentrations in soil solution. According to Huang et al. (1997), in most of the contaminated soils they examined, lead content in soil solution amounted to less than $0.1 \%$ of the total lead content in the soil. Also, Kališova-Špirochova et al. (2003) found that in a highly polluted industrial area, where contaminated soil contained $16000 \mathrm{mg} \cdot \mathrm{kg}^{-1}$ of $\mathrm{Pb}^{2+}$, the content of lead in water leachate was just $0.45 \mathrm{mg} . \mathrm{I}^{-1}$ (i.e. $5.49 \mu \mathrm{M})$. Thus, it seems that genotypes should be selected in order to achieve vigorous growth on substrates polluted with lead in relatively tolerable concentrations.

In concordance with the results from some previous works (Kališova-Špirochova et al. 2003, Katanić et al. 2007, di Lonardo et al. 2011, Kovačević et al. 2013a), in most of the examined media no signs of intoxication were found on shoots. In this work, only sporadic necrotic changes were found on the roots formed in medium with $10^{-3} \mathrm{M} \mathrm{Pb}\left(\mathrm{NO}_{3}\right)_{2}$, which is consistent with the results by Kovačević et al. (2013a) on the same medium. However, Bojarczuk (2004) reported an inhibitory effect of the medium with $\mathrm{pH} 5.5$ and $2.0 \mathrm{mM} \mathrm{Pb}\left(\mathrm{NO}_{3}\right)_{2}$ on shoot and root development of calli of hybrid aspen on regeneration medium. On medium with 1.0 $\mathrm{mM} \mathrm{Pb}\left(\mathrm{NO}_{3}\right)_{2}$ they found that all traits, except shoot height, did not differ significantly from that in the control medium. This is in concordance with the results we gained on our L4 medium, which contained the same concentration of lead nitrate, and where the tolerance indices were around 1 for all examined traits.

Tolerance indices for shoot height and length of the longest root were mostly below 1 on L3 and L4 media, and above 1 on L1 and L2 media, indicating inhibition of shoot and root growth on high, and stimulating effect on low lead concentrations. These results are in accordance with the results by Seregin and Ivanov (2001), who found that low lead concentrations promote root growth. Baker and Walker (1989) extensively discuss the stimulative effect of low concentrations of heavy metals in a substrate, stressing that this phenomenon should be further examined, especially in non-essential metals, such as lead.

Different parameters that describe root growth and analog tolerance index are extensively used in heavy metal tolerance studies in plants (Baker and Walker, 1989). In our work the tolerance index for the number of roots was under the weak influence of the factor Medium, while Kovačević et al. (2013a) reported that this influence was significant and the presence of lead in the medium appeared to be stimulative. However, the effect of the factor Medium on tolerance index for the length of the longest root in their study was not significant, while in our work the inhibitory effect of high lead concentrations was significant. It could be assumed that these differences in results are caused by higher bioavailability of lead and consequently its higher toxicity in media studied in our work due to low $\mathrm{pH}$ and the presence of citric acid as a chelating agent in media, which is in concordance with the results by Yang et al. (2006).

Tolerance indices based on dry shoot and dry root mass accumulation were mostly higher than 1 , suggesting the stimulating effect of the examined media on biomass accumulation, except for the inhibitory effect on dry root mass accumulation on L3 medium. Kališova-Špirochova et al. (2003) reported the stimulating effect of $10^{-4} \mathrm{M} \mathrm{Pb}^{2+}$ on total plant biomass accumulation in aspen rooted shoots in liquid

Table 4. Tolerance indices for content of photosynthetic pigments in white poplar genotypes grown on different concentrations of $\mathrm{Pb}\left(\mathrm{NO}_{3}\right)_{2}$ (Fisher's LSD test).

$\left.{ }^{*}\right)$ The differences between values marked with the same letter are not significant at the level $\alpha=0.05$

\begin{tabular}{ccccc}
\hline $\begin{array}{c}c\left(\mathrm{~Pb}\left(\mathrm{NO}_{3}\right)_{2}\right) \\
(\mathrm{M})\end{array}$ & $\begin{array}{c}\text { Chlorophyll a } \\
\text { content }\end{array}$ & $\begin{array}{c}\text { Chlorophyll b } \\
\text { content }\end{array}$ & $\begin{array}{c}\text { Chlorophyll } \mathrm{a}+\mathrm{b} \\
\text { content }\end{array}$ & $\begin{array}{c}\text { Carotenoides } \\
\text { content }\end{array}$ \\
\hline $10^{-6}$ & $0.898^{\mathrm{b}}{ }^{*}$ & $0.990^{\mathrm{ab}}$ & $0.923 \mathrm{~b}$ & $0.852 \mathrm{~b}$ \\
$10^{-5}$ & $0.903^{\mathrm{b}}$ & $0.882^{\mathrm{b}}$ & $0.897 \mathrm{~b}$ & $0.898 \mathrm{~b}$ \\
$10^{-4}$ & $0.8688^{\mathrm{b}}$ & $0.855^{\mathrm{b}}$ & $0.864 \mathrm{~b}$ & $0.877 \mathrm{~b}$ \\
$10^{-3}$ & $1.180^{\mathrm{a}}$ & $1.189 \mathrm{a}$ & $1.182 \mathrm{a}$ & $1.156 \mathrm{a}$ \\
\hline
\end{tabular}


medium in vitro. In concordance with our results, Katanić et al. (2007) found inhibitory effect of $10^{-4} \mathrm{M} \mathrm{Pb}$.EDTA in growing medium on fresh biomass accumulation of white poplar shoots. Although necrotic changes were found on roots formed on $\mathrm{L} 4$ medium $\left(10^{-3} \mathrm{M} \mathrm{Pb}\left(\mathrm{NO}_{3}\right)_{2}\right)$, the stimulating effect of this medium on biomass accumulation was found in our work. This stimulation was probably caused by the nitrogenous component of lead nitrate, whose quantity was increased in this medium by $20 \%$ compared to control. While Bojarczuk (2004) used a twice as high concentration of $\mathrm{Pb}\left(\mathrm{NO}_{3}\right)_{2}$ to achieve the inhibitory effect, with lower $\mathrm{pH}$ and the presence of citrate acid, as a chelating agent, L3 medium achieved the inhibitory effect with a much lower concentration of lead, which is more likely to be found in the field (Kališova-Špirochova et al. 2003). These findings favor this medium to be used in further lead tolerance testing. However, the best genotype differentiation according to tolerance indices for most of the examined morphological and biomass traits was achieved on $\mathrm{L} 2$ medium $\left(10^{-5} \mathrm{M}\right.$ $\left.\mathrm{Pb}\left(\mathrm{NO}_{3}\right)_{2}\right)$. Therefore, this medium should also be taken into consideration, especially in the evaluation of white poplar genotypes that would be used in afforestation of soils that are moderately contaminated with lead.

Regarding the content of photosynthetic pigments as a stress marker (Ghnaya et al. 2009), our results suggest a significant effect of the examined media on most photosynthetic characters, except chlorophyll a/b ratio. The strongest inhibitory effect was achieved on $\mathrm{L} 2$ and $\mathrm{L} 3$ media. The effect of L4 medium was stimulating, probably for the same reason as we assumed for biomass accumulation characters. However, Kovačević et al. (2013a) gained no such effects on media with pH 5.5 and with no chelating agents.

Extensive research has been done in describing the inhibitory effect of the high and stimulating effects of low lead concentrations on the content of photosynthetic pigments (Ewais 1997, Sarvari et al. 2002, Kaznina et al. 2005, Zengin and Munzuroglu 2005). According to Seregin and Ivanov (2001), the lead in toxic concentrations is responsible for restrained chlorophyll synthesis, resulting in decreased chlorophyll content. The same authors state that chlorophyll $b$ is more affected than chlorophyll $a$, while numerous authors suggest decrement of chlorophyll a/b ratio on high lead concentrations (Sarvari et al. 2002, Kamel 2008, Kovačević et al. 2013a). However, the results of our research show that tolerance indices for the examined photosynthetic characters of the studied genotypes within the same medium were relatively similar, with no significant effect of factor Medium on tolerance index for chlorophyll $\mathrm{a} / \mathrm{b}$ ratio.

In order to achieve a more critical test for the evaluation of white poplar genotypes for use in phytoremediation projects, we used modified medium with the intention to increase the bioavailability of lead by increasing its mobility both by lowering the $\mathrm{pH}$ and using citric acid as a chelating agent (Yang et al. 2006). Beside general benefits in lead testing in vitro, test on acidic media could be especially important for situations where heavy metal pollution is accompanied by acidification of soil, such as soil pollution after accidents in mining facilities (Antonijević and Marić 2008).
In comparison with the results gained by Kovačević et al. (2013a) on media with pH 5.5, it can be assumed that a stronger effect of lead in our work was achieved by lowering $\mathrm{pH}$ and using citric acid. Likewise, Vuksanović et al. (2017b) gained toxic effect and total absence of rooting of Populus nigra in medium with $\mathrm{pH} 3$ and $10^{-3} \mathrm{M} \mathrm{Cu}^{2+}$, while di Lonardo et al. (2011) reported absence of toxic effect on Populus alba for the same concentration of copper in medium with $\mathrm{pH}$ 5.2 .

Generally, differences in lead tolerance between the examined genotypes were rather low and mostly nonsignificant. However, regarding tolerance indices obtained on L2 and L3 media, the differences between the examined genotypes can be discussed and their lead tolerance can be evaluated. In this case, genotype Villafranca was used as a standard, regarding its frequent use in biotechnological studies and its good in vitro performance in the presence of lead and some other heavy metals (di Lonardo et al. 2011). According to both length of the longest root and shoot height, genotype L-12 achieved the best tolerance, and together with LBM had the greatest tolerance indices, higher than 1 . According to dry root and shoot mass accumulation, best tolerance achieved LCM which, together with L-12, achieved tolerance indices higher than 1 . It was not possible to differentiate genotypes by examined photosynthetic characters neither on medium L3 nor on medium L2. Thus, considering the obtained results, it can be assumed that the genotype with the best performance in lead tolerance is genotype L-12, followed by LBM and LCM. Also, all examined genotypes achieved better lead tolerance than standard Villafranca genotype. These results are in accordance with Kovačević et al. (2013a), who obtained the best differentiation of white poplar genotypes on the medium with $\mathrm{pH} 5.5$ and $10^{-4} \mathrm{M} \mathrm{Pb}\left(\mathrm{NO}_{3}\right)_{2}$, the highest tolerance index for shoot height was achieved by L-12 and L-80, while the highest tolerance indices for dry shoot accumulation were recorded for LBM and LCM. The most striking difference between two studies is the reaction of genotype L-80. In our and also in the work by Vuksanović et al. (2019b) L-80 achieved relatively good growth performance on control medium with pH 3 (see Supplementary File). However, in our study this genotype achieved lowest tolerance indices of all genotypes on lead treatment media L2 and L3 for the majority of examined traits, while its performance on lead treatment media with $\mathrm{pH} 5.5$ in the work by Kovačević et al. (2013a) was relatively good. Thus, it seems that the low lead tolerance of genotype L-80 in our study is specifically a reaction to enhanced bioavailability of lead in conditions of low $\mathrm{pH}$ and in the presence of a chelating agent.

Baker and Walker (1989) discussed positively the use of tissue culture in heavy metal tolerance studies in plants, emphasizing the possibility of faster tolerance testing with a smaller amount of material and without destruction of the mother plant. Watson et al. (2003) and Pulford et al. (2002) demonstrated in Salix sp. that the results obtained in hydroponics and in the field are comparable. Doran (2009) and Capuana (2011) elaborated that the response of plants to environmental contaminants can be predicted on the basis of the results from tissue cultures, which would reduce the necessity and costs of conventional field experiments. It 
could be assumed that changes made in media proposed in this work in course of the increased bioavailability of lead would decrease differences between the results obtained in vitro and in field conditions. However, for final evaluation, further research should be performed in order to relate data from in vitro to field conditions, considering lower availability of lead in soil, higher juvenility of the material in vitro, and complexity of the interaction between plant and habitat.

\section{CONCLUSIONS}

According to the presented results, the presence of citric acid in the medium with low $\mathrm{pH}$ enforced the toxic effect of lead compared to previous similar studies. The strongest toxic effect was found for the medium with $10^{-4}$ $\mathrm{M} \mathrm{Pb}\left(\mathrm{NO}_{3}\right)_{2}$ but the best differentiation between genotypes was achieved on medium with $10^{-5} \mathrm{M} \mathrm{Pb}\left(\mathrm{NO}_{3}\right)_{2}$. According to most of the examined parameters, lead tolerance in genotypes L-12, LBM, and LCM was better than in standard Villafranca genotype. Results of this work support the further application of in vitro tests in heavy metal tolerance research and evaluation in white poplar genotypes.

\section{Author Contributions}

BK, TG, NN conceived and designed the research, BK and GT performed laboratory analysis, BK, TG and VV processed the data and performed the statistical analysis, SO secured the research funding, supervised the research and helped to draft the manuscript, BK, GT and $\mathrm{MM}$ wrote the manuscript.

\section{Funding}

This research has been fully supported by the Ministry of Education, Science and Technological Development of the Republic of Serbia (Project No: 451-03-68/2020-14/200197 and Project No: 451-03-68/2020-14/ 200117).

\section{Conflicts of Interest}

The authors declare no conflict of interest.

\section{REFERENCES}

Aitchison EW, Kelley SL, Alvarez PJJ, Schoor JL, 2000. Phytoremediation of 1,4-dioxane by hybrid poplar trees. Water Environ Res 72(3): 313-321. https://doi. org/10.2175/106143000X137536.

Antonijević M, Marić M, 2008. Determination of the content of heavy metals in pyrite contaminated soil and plants. Sensors 8(9): 5857-5865. https://doi.org/10.3390/s8095857.

Arora M, Kiran B, Rani S, Rani A, Kaur B, Mittal N, 2008. Heavy metal accumulation in vegetables irrigated with water from different sources. Food Chem 111(4): 811-815. https://doi. org/10.1016/j.foodchem.2008.04.049.

Baker AJM, Walker PL, 1989. Physiological responses of plants to heavy metals and the quantification of tolerance and toxicity. Chem Speciat Bioavailab 1(1): 7-17. https://doi.org/10.1080/ 09542299.1989.11083102.

Benavides MP, Gallego SM, Tomaro ML, 2005. Cadmium toxicity in plants. Braz J Plant Physiol 17(1): 21-34. https://doi. org/10.1590/S1677-04202005000100003.

Bittsanszky A, Komives T, Gullner G, Gyulai G, Kiss J, Heszky L, Radimszky L, Rennenberg H, 2005. Ability of transgenic poplars with elevated glutathione content to tolerate zinc(2+) stress. Environ Int 31(2): 251-254. https://doi.org/10.1016/i. envint.2004.10.001.

Bojarczuk K, 2004. Effect of toxic metals on the development of poplar (Populus tremula L. x P. alba L.) cultured in vitro. Pol J Environ Stud 13(2): 115-120.

Capuana M, 2011. Heavy metals and woody plants biotechnologies for phytoremediation. iForest 4(1): 7-15. https://doi.org/10.3832/ifor0555-004.

Castiglione S, Franchin C, Fossati T, Lingua G, Torrigiani P, Biondi $S, 2007$. High zinc concentrations reduce rooting capacity and alter metallothionein gene expression in white poplar (Populus alba L. cv. Villafranca). Chemosphere 67(6): 11171126. https://doi.org/10.1016/i.chemosphere.2006.11.039.

Confalonieri M, Balestrazzi A, Bisoffi S, Carbonera D 2003. In vitro culture and genetic engineering of Populus spp.: synergy for forest tree improvement. Plant Cell Tissue Org Cult 72: 109138. https://doi.org/10.1023/A:1022265504775.
Doran PM, 2009. Application of Plant Tissue Cultures in Phytoremediation Research: Incentives and Limitations. Biotechnol Bioeng 103(1): 60-76. https://doi.org/10.1002/ bit.22280.

Ewais EA, 1997. Effects of cadmium, nickel and lead on growth, chlorophyll content and proteins of weed. Biol Plant 39(3): 403-410. https://doi.org/10.1023/A:1001084327343.

Ghnaya AB, Charles G, Hourmant A, Hamida JB, Branchard $M, 2009$. Physiological behaviour of four rapeseed cultivar (Brassica napus L.) submitted to metal stress. CR Biol 332: 363-370. https://doi.org/10.1016/j.crvi.2008.12.001.

Huang JW, Chen J, Berti WR, Cunningham SD, 1997. Phytoremediation of Lead-Contaminated Soils: Role of Synthetic Chelates in Lead Phytoextraction. Environ Sci Technol 31(3): 800-805. https://doi.org/10.1021/es9604828.

Ištok I, Šefc B, Sedlar T, Goršić E, Mihić M, Stojnić S, 2019. Fiber length in clone L-12 juvenile wood. Topola(Poplar) 203: 37-43.

Kališova-Špirochova I, Punčocharova J, Kafka Z, Kubal M, Soudek $P$, Vanek T, 2003. Accumulation of heavy metals by in vitro cultures of plants. Water Air Soil Pollut : Focus 3: 269-276. https://doi.org/10.1023/A:1023933902452.

Kamel HA, 2008. Lead accumulation and its effect on photosynthesis and free amino acids in Vicia faba grown hydroponically. Aust. J Basic App/ Sci 2(3): 438-446.

Katanic M, Pilipovic A, Orlovic S, Krstic B, 2007. The influence of lead on the shoot growth and concentration of photosynthetic pigments in leaves of the white poplar (Populus alba) clones in vitro. Topola(Poplar) 179/180: 15-24.

Katanic M, Pilipovic A, Orlovic S, Krstic B, Kovacevic B, Pekec $S, 2008$. The influence of nickel, cadmium and lead on the growth of the white poplar clones' shoots in vitro. In: Orlovic $S$ (ed) Proceedings of International scientific conference "Forestry in achieving millennium goals", Novi Sad, Serbia, 13-15 November 2008. Institute of lowland forestry and environment, Novi Sad, Serbia, pp 295-301.

Kaznina NM, Laidinen GF, Titov AF, Talanov AV, 2005. Effect of Lead on the Photosynthetic Apparatus of Annual Grasses. Biology Bulletin 32(2): 147-150. 
Kovačević B, Miladinović D, Orlović S, Katanić $M$, Kebert $M$, Kovinčić J, 2013a. Lead Tolerance and Accumulation in White Poplar Cultivated In Vitro. South-east Eur for 4(1): 3-12. https://doi.org/10.15177/seefor.13-01.

Kovačević B, Miladinović D, Katanić M, Tomović Z, Pekeč S, 2013b. The effect of low initial medium $\mathrm{pH}$ on in vitro white poplar growth. Bull Fac Forest 108: 67-80.

Kovačević B, Igić D, 2018. Effect of early preparation and slope aspect on survival and growth of white poplar rooted cuttings. Topola(Poplar) 205: 117-126.

Kovačević B, Igić D, Novčić Z, Orlović S, 2020. Survival and growth of white poplar rooted cuttings regarding term of planting. Topola(Poplar) 205: 33-46.

Di Lonardo S, Capuana M, Arnetoli M, Gabbrielli R, Gonnelli $C$, 2011. Exploring the metal phytoremediation potential of three Populus alba L. clones using an in vitro screening. Environ Sci Pollut Res 18: 82-90. https://doi.org/10.1007/ s11356-010-0354-7.

Pulford ID, Riddell-Black D, Stewart C, 2002. Heavy metal uptake by willow clones from sewage sludge-treated soil: the potential for phytoremediation. Int J Phytoremediat. 4(1): 5972. https://doi.org/10.1080/15226510208500073.

Pulford ID, Watson C, 2003. Phytoremediation of heavy metalcontaminated land by trees - a review. Environ Int 29(4): 529540. https://doi.org/10.1016/S0160-4120(02)00152-6.

Rani V, Raina SN, 2000. Genetic fidelity of organized meristemderived micropropagated plants: A critical reappraisal. In Vitro Cell Dev Biol Plant 36: 319-330. https://doi.org/10.1007/ s11627-000-0059-6.

Rockwood DL, Naidu CV, Carter DR, Rahmani M, Spriggs TA, Lin C, Alker GR, Isebrands JG, Segrest SA, 2004. Shortrotation woody crops and phytoremediation. Opportunities for agroforestry? Agrofor Syst 61(1): 51-63. https://doi. org/10.1023/B:AGFO.0000028989.72186.e6.

Sakan SM, Đorđević DS, Manojlović DD, Polić PS, 2009. Assessment of heavy metal pollutants accumulation in the Tisza river sediments. J Environ Manage 90(11): 3382-3390. https://doi.org/10.1016/j.jenvman.2009.05.013.

Sarvari E, Gaspar L, Fodor F, Cseh E, Kroepfl K, Varga A, Baron M, 2002. Comparison of the effect of $\mathrm{Pb}$ treatment on thylacoid development in poplar and cucumber plant. Acta Biologica Szegediensis 46(3-4): 163-165.

Sedlar T, Ištok I, Orešković G, Stojnić S, Goršić E, Šefc B, 2019. Physical properties of wood in white poplar clone "L-12" grown in Republic of Croatia and Serbia. Topola(Poplar) 203: 45-51.

Seregin IV, Ivanov VB, 2001. Physiological aspects of cadmium and lead toxic effects on higher plants. Russ J Plant Physiol 48(4): 523-544. https://doi.org/10.1023/A:1016719901147.

Sharma P, Dubey RS, 2005. Lead toxicity in plants. Braz J Plant Physio. 17(1): 35-52. https://doi.org/10.1590/S167704202005000100004 .
Sinhal VK, Srivastava A, Singh VP, 2010. EDTA and citric acid mediated phytoextraction of $\mathrm{Zn}, \mathrm{Cu}, \mathrm{Pb}$ and $\mathrm{Cd}$ through marigold (Tagetes erecta). J Environ Biol 31(3): 255-259.

Skirvin RM, Chu MC, Mann ML, 1986. Stability of tissue culture medium $\mathrm{pH}$ as a function of autoclaving, time and cultured plant material. Plant Cell Rep 5: 292-294. https://doi. org/10.1007/BF00269825.

TIBCO Software Inc. 2017. Statistica (data analysis software system), version 13. Available online: https://docs.tibco.com/ products/tibco-statistica-13-3-0 (20 October 2020).

Turner RC, Marshal C, 1972. The accumulation of zinc by subcellular fractions of roots of Agrostis tenuis Sibth. in relation to zinc tolerance. New Phytol 71(4): 671-676. https:// doi.org/10.1111/j.1469-8137.1972.tb01277.x.

Vuksanović V, Kovačević B, Orlović S, Kebert M, Katanić M, 2016. The influence of rooting medium $\mathrm{pH}$ on the growth and development of shoots of white poplar in vitro. Topola(Poplar) 197/198: 51-63.

Vuksanović $\mathrm{V}$, Kovačević $\mathrm{B}$, Orlović $\mathrm{S}$, Miladinović $\mathrm{D}$, Katanić $\mathrm{M}$, Kebert M, 2017a. Changes in medium pH during white poplar micropropagation. Topola(Poplar) 199/200: 153-165.

Vuksanović V, Kovačević B, Katanić M, Orlović S, Miladinović D, 2017b. In vitro Evaluation of Copper Tolerance and Accumulation in Populus nigra. Arch Biol Sci 69(4): 679-687. https://doi.org/10.2298/ABS170210014V.

Vuksanović V, Kovačević B, Orlović S, Kebert M, Kovač M, 2019a. Influence of drought on growth and development of white poplar shoots in vitro. Topola(Poplar) 203: 13-18.

Vuksanović V, Kovačević B, Kebert M, Katanić M, Pavlović L, Kesić L, Orlović S, 2019b. Clone specificity of white poplar (Populus alba L.) acidity tolerance in vitro. Fresen Environ Bull 28(11): 8307-8313.

Watson C, Pulford ID, Riddell-Black D, 2003. Screening of willow species for resistance to heavy metals: Comparison of performance in a hydroponics system and field trials. Int J Phytoremediat 5(4): 351-365. https://doi. org/10.1080/15226510309359042.

Wettstein D, 1957. Chlorophyll-lethal and the submicroscopic shape change of the plastids. Exp Cell Res 12: 427-506.

Yang JY, Yang XE, He ZL, Li TQ, Shentu JL, Stoffella PJ, 2006. Effects of $\mathrm{pH}$, organic acids, and inorganic ions on lead desorption from soils. Environ Pollut 143(1): 9-15 https://doi. org/10.1016/i.envpol.2005.11.010.

Zengin FK, Munzuroglu O, 2005. Effects of some heavy metals on content of chlorophyll, proline and some antioxidant chemicals in bean (Phaseolus vulgaris L.) seedlings. Acta Biol Cracov Bot. 47/2: 157-164.

Zhang Y, 2003. 100 Years of $\mathrm{Pb}$ deposition and transport in soils in Champaign, Illinois, U.S.A. Water Air Soil Pollut 146: 197-210. https://doi.org/10.1023/A:1023957226204. 